\title{
Patients' evaluation of hospital foodservice quality in Italy: what do patients really value?
}

\author{
Gabriele Messina ${ }^{1, *}$, Roberto Fenucci ${ }^{2}$, Francesco Vencia ${ }^{1}$, Fabrizio Niccolini ${ }^{2}$, \\ Cecilia Quercioli ${ }^{1}$ and Nicola Nante ${ }^{1}$ \\ 'Department of Public Health, Health Services Research Laboratory, University of Siena, Via Aldo Moro 2, \\ 53100 Siena, Italy: ${ }^{2}$ Teaching Hospital Careggi, Largo Brambilla, Florence, Italy
}

Submitted 29 0ctober 2011: Final revision received 1 March 2012: Accepted 4 June 2012: First published online 8 August 2012

\begin{abstract}
Objective: Patients often do not eat/drink enough during hospitalization. To enable patients to meet their energy and nutritional requirements, food and catering service quality and staff support are therefore important. We assessed patients' satisfaction with hospital food and investigated aspects influencing it. Design: We conducted a cross-sectional study collecting patients' preferences using a slightly modified version of the Acute Care Hospital Foodservice Patient Satisfaction Questionnaire (ACHFPSQ). Factor analysis was carried out to reduce the number of food-quality and staff-issue variables. Univariate and multivariate ordinal categorical regression models were used to assess the association between food quality, staff issues, patients' characteristics, hospital recovery aspects and overall foodservice satisfaction (OS).

Setting: A university hospital in Florence, Italy, in the period NovemberDecember 2009.

Subjects: Hospital patients aged $18+$ years ( $n$ 927).

Results: Of the 1288 questionnaires distributed, 927 were returned completely or partially filled in by patients and 603 were considered eligible for analysis. Four factors (explained variance $64 \cdot 3 \%$, Cronbach's alpha $\alpha_{C}=0.856$ ), i.e. food quality (FQ; $\alpha_{\mathrm{C}}=0.74$ ), meal service quality (MSQ; $\alpha_{\mathrm{C}}=0.73$ ), hunger and quantity (HQ; $\left.\alpha_{\mathrm{C}}=0.74\right)$ and staff/service issues (SI; $\alpha_{\mathrm{C}}=0.65$ ), were extracted from seventeen items. Items investigating staff/service issues were the most positively rated while certain items investigating food quality were the least positively rated. After ordinal multiple regression analysis, OS was only significantly associated with the four factors: FQ, MSQ, HQ and SI (OR $=17 \cdot 2$, $6 \cdot 16,3.09$ and 1.75 , respectively, $P<0.001$ ), and gender (OR $=1.53, P=0.024)$. Conclusions: The most positively scored aspects of foodservice concerned staff/ service, whereas food quality was considered less positive. The aspects that most influenced patients' satisfaction were those related to food quality.
\end{abstract}

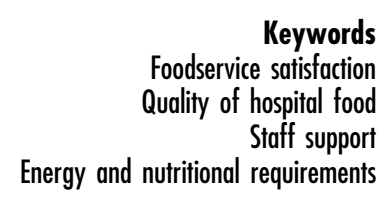

An important aspect influencing patients' satisfaction with hospital stay is their relationship to food, nutrition being a part of hospital care. Moreover, the role of the hospital foodservice has become increasingly important because of problems associated with malnutrition ${ }^{(1-4)}$.

Food should meet patients' needs, help to eat and drink should be provided when necessary and food should be presented appropriately and consumed in a pleasant environment ${ }^{(5)}$. Hospital menus should be planned according to patients' preferences, focusing on variety, quality and taste, as well as hospital environment and pleasant helpfulness of nursing staff. This is a new qualitative approach to a complex problem $^{(6-8)}$. Context, including indirect environmental/cultural factors, indirect personal factors and socio-cultural aspects occurring before, during and after hospitalization, has also been identified as an important factor in understanding acceptance of food and in predicting food consumption $^{(9-13)}$. However, few instruments to measure customer satisfaction exist and it is difficult to convert results into protocols and practices. Surveys usually have the limitation of asking very few general questions about foodservice, which are insufficient to obtain detailed feedback about objective and interpersonal aspects from patients and to investigate patients' desire for personalized service. However, knowledge of these features seems to be an important basis from which to measure the impact of foodservice innovations or patients' foodservice satisfaction outcomes in time ${ }^{(14,15)}$. Several studies concerned with influences on foodservice satisfaction have been 
published, especially in the USA and Canada, but the relationships between consumer satisfaction, perceived quality and foodservice characteristics are largely unexplored $^{(9,16,17)}$.

Evidence in this field is still lacking in our country (Italy); to our knowledge, only a few studies ${ }^{(16,18)}$ have raised these aspects. Therefore the aims of the present study were to: (i) measure patient satisfaction with foodservice in a big Italian university hospital; and (ii) study the influence of variables related to patient characteristics, hospital admission and food catering on overall perceived satisfaction.

\section{Methods}

\section{Setting}

The survey was carried out in Careggi Hospital, a publicly financed university hospital in Florence, Tuscany, central Italy. It is a highly specialized centre with 1500 beds and about 60000 ordinary admissions and 73000 day admissions per year. Patients are from the Province of Florence (population about 970000 ), other Tuscan provinces and other Italian regions. Mean hospital stay is about $8 \mathrm{~d}^{(19)}$. The study period was 1 November to 15 December 2009, and involved in-patients of fifty-five wards. The hospital has pavilion architecture and the food is prepared in a centralized kitchen. The foodservice is 'cook-hot hold' type. The type and quantity of food for each ward is loaded into (refrigerated and heated) food containers and is transported to the wards from the central kitchen by electric indoor buses. In the wards, nurses/nursing assistants load the container into trolleys, wheel them to all the rooms and serve an appropriate portion at every bedside. When no food restrictions apply, patients may choose between two or three hot first courses (mainly pasta, rice or soup), two or three main courses (mainly chicken, beef or fish) and two or three vegetables (mainly mashed potatoes or steamed vegetables) plus fresh fruit.

Meals are served three times daily: breakfast at 07.30-08.30 hours, lunch at 12.00-12.30 hours and dinner at 19.00-19.30 hours. Nurses do not distribute other food outside mealtimes, except fruit or yoghurt (late morning) and hot tea in the afternoon in some wards.

The food is ordered by the nurse responsible for the ward on the basis of the medical prescription on the clinical chart (without restrictions, modified texture, dysphagic, diabetic, high energy, high protein, etc.). Nutritional risk is evaluated and managed by doctors and nurses using a Malnutrition Universal Screening $\mathrm{Tool}^{(20)}$ chart which identifies three nutritional levels (low, medium, high) of patients. In the case of high risk, a dietitian is consulted and the diet is prescribed by the doctor and dietitian.

The estimated cost per meal may vary (preparation in/out of hospital, type of meal, etc.). The estimated cost of a meal in Careggi Hospital is about $€ 11$ (\$US 15.98).

\section{The questionnaire}

Data were collected using a slightly modified version of the Acute Care Hospital Foodservice Patient Satisfaction Questionnaire (ACHFPSQ) ${ }^{(15,21)}$ (see Table 2). Most nutritional screening tools do not measure various aspects that influence poor food intake and undernutrition. Since the ACHFPSQ differentiates foodservice into several detailed aspects, it is considered more effective in identifying specific areas in need of correction ${ }^{(17,22)}$. It was administered by nurses who could answer any questions patients might have. The ACHFPSQ is a reliable validated tool which gathers general information on the patients' age, gender, length of hospital stay, appetite status (measured as food intake quantity), diet type (standard, high energy, high protein, modified for clinical reasons, texture modified) and need for help to answer the questionnaire $^{(15,23)}$. It comprises sixteen questions investigating the following dimensions: Food Quality (FQ), Meal Service Quality (MSQ), Staff/service Issues (SI) and Physical Environment (PE), plus two questions not included in these dimensions and one question investigating overall satisfaction (OS). We decided to include three more questions related to a fifth dimension, 'Hunger and Food Quantity' (HQ), which are not part of the published ACHFPSQ, but are part of the survey, because: (i) in the guidelines of the ACHFPSQ, this fifth dimension hunger and food quantity - is described and it is identified by three additional questions; (ii) we felt that the three questions could be pertinent to the study; and (iii) we found that they have been used also in other research ${ }^{(21)}$. Patients could also write comments on the questionnaire ${ }^{(21,24)}$.

We translated the questionnaire into Italian and then asked a translator whose mother tongue was English to translate it back into English again to check for errors, distortions and misinterpretations in the English-Italian translation. Finally, using other Italian questionnaires ${ }^{(25,26)}$ which investigate patient satisfaction with food, and to better adapt the ACHFPSQ to the Italian hospital context, we rephrased the item 'The crockery and cutlery are chipped and/or stained' to 'I am satisfied with crockery and cutlery' to make the question more direct and we changed the item 'The cold drinks are just at the right temperature' to 'I am satisfied with meal distribution time' because there were other questions related to the temperature aspects and this one, from a prior discussion with dietitians, emerged to be less important, at least in the Italian context, while a question regarding the meal distribution time was missing and was of interest also to other research. The questionnaire took approximately $15 \mathrm{~min}$ to fill in (alone or with nursing staff help). Patients rated each statement on a 5-point scale (always/often/sometimes/rarely/never) and expressed overall satisfaction with foodservice from very good to very poor. Adult patients (18+ years) were enrolled using nonprobability sampling (convenience sampling) ${ }^{(27)}$. Patients were excluded if nursing staff considered their condition too poor or if they were not served food (no oral diet) or 
were too confused to answer or provide consent. Patients who did not wish to participate in the study returned a blank questionnaire. Patients' names were not recorded.

\section{Data collection and management}

The authorization by and support of the hospital health management enabled good organization in distributing the questionnaire and the project was explained to nurses.

Questionnaires were distributed by nurses or other hospital staff according to the guidelines. The questionnaires were brought to patients on the food tray. Nurses explained that it was anonymous and authorized by the hospital administration for the purpose of improving catering. Questionnaires could be returned to nurses or other hospital personnel. Nurses had access to the completed questionnaires but it is unlikely that they influenced patient' choices because questionnaires were anonymous and filled in by patients. Moreover, nurses were not responsible for food preparation. Finally, the questionnaire guidelines stated that health-care personnel could provide assistance in cases of difficulty in filling in the questionnaire.

All of the questionnaires were processed using the optical mark recognition software Remark Office version 7•0 (Gravic Inc., Malvern, PA, USA), which allowed us to standardize questionnaire reading methods in an efficient way. In cases of possible misinterpretation of marks, the software alerts the user so that the correct choice can be selected manually. All questionnaires were automatically stored in a database and later exported for statistical analysis.

\section{Statistical analysis}

Descriptive analysis (mean and percentages) was used to describe patients' characteristics and answers to questionnaire items. To account for possible selection bias between respondents and non-respondents to all ACHFPSQ items, we conducted $\chi^{2}$ tests for statistical significance. Factor analysis was then carried out to reduce multiple variables and the number of underlying factors describing catering and food characteristics. We used an intercorrelation matrix to account for collinearity of variables. Bartlett's test of sphericity was used to assess factorability of the intercorrelation matrix. Factors were extracted based on eigenvalues $>1$ (that explain more variance than a single variable) ${ }^{(9)}$. We chose varimax rotation to maximize the items in factor patterns. Items that did not fit any factor but had explanatory power were considered and analysed independently; indeed, factors were only included in the analysis if they contained at least three items ${ }^{(28)}$. Items scoring less than 0.4 on the factor were not included. Items grouped within a factor but also highly correlated with one or more factors (making factor interpretation ambiguous) were omitted ${ }^{(28)}$. To determine the factor score, also in accordance with the ACHFPSQ guideline, all items had to be answered. In fact, to maximize the validity of our results we opted for listwise deletion, excluding records lacking answers to even a single item, rather than creating predictors for distribution of missing values, which make it impossible to verify the consistency of derived models depending on the imputation method chosen ${ }^{(29)}$. Missing answers have to be dealt with cautiously as they may introduce distortions ${ }^{(30)}$. The reliability of the questionnaire and the internal consistency of factors were evaluated by Cronbach's alpha coefficient $\left(\alpha_{\mathrm{C}}\right)$. Statistical significance was assessed at the 5\% level. Univariate and multiple ordinal regression analyses were used to investigate the influence of the factors obtained, age, gender, appetite status, patients' diet type and length of hospital stay on overall perceived satisfaction measured on a 5-point scale (from very poor to very good). The multiple ordinal regression models only included variables that proved to be associated with the outcome at univariate analysis level. Descriptive analysis, as well as univariate and multiple ordinal regression, were conducted with the STATA statistical software package version 8 (StataCorp LP) and factor analysis was conducted with the SPSS statistical software package version 10 (SPSS Inc.).

\section{Ethics}

The study was conducted with the permission of the administration of Careggi University Hospital. The information about patients was anonymous and was obtained on a voluntary basis.

\section{Results}

A total of 1288 questionnaires were distributed and 927 were collected (overall response rate $72 \%$ ). Questionnaires were not returned by Orthopaedics, Urology, Gastroenterology and Day Hospital. After screening for missing answers to items included in factors, the total of questionnaires eligible for analysis was 603. The $\chi^{2}$ tests for statistical significance did not highlight differences in characteristics of respondents and non-respondents to all ACHFPSQ items (Table 1).

Regarding the sample of respondents, the mean age was $54 \cdot 0(\mathrm{sD} 18 \cdot 0)$ years, with almost $25 \%$ in the age group $>70$ years; $50 \cdot 6 \%$ were males. Of the sample, $57 \cdot 4 \%$ recorded 'normal appetite', 66.1\% had a standard/diabetic/cardiac diet and $56.9 \%$ stayed in hospital for less than 1 week. Survey results are shown in Table 2. Items investigating staff/service issues were the most positively rated $(83.4 \%$ answered that staff who delivered meals were always neat and clean; $70 \cdot 7 \%$ that staff who took away finished meals were friendly and polite; $60.0 \%$ that staff who delivered meals were helpful). Some items investigating food quality were the least positively rated $(56 \cdot 6 \%$ answered that hospital food was sometimes/rarely/never as good as expected; $64.3 \%$ answered that they sometimes/rarely/never liked the way vegetables were cooked; $60 \cdot 0 \%$ answered that meals had sometimes/rarely/never excellent and distinct flavours). 
Table 1 Characteristics (\%) of the study population, overall and according to response to all ACHFPSQ items: hospital patients aged 18+ years, Florence, Italy, November-December 2009

\begin{tabular}{|c|c|c|c|c|}
\hline & $\begin{array}{l}\text { Overall } \\
(n \text { 927) }\end{array}$ & $\begin{array}{l}\text { Respondents to all } \\
\text { ACHFPSQ items }(n 603)\end{array}$ & $\begin{array}{l}\text { Non-respondents to all } \\
\text { ACHFPSQ items }(n \text { 324) }\end{array}$ & $P$ \\
\hline \multicolumn{5}{|l|}{ Gender (\%) } \\
\hline Males & $49 \cdot 3$ & $50 \cdot 6$ & $46 \cdot 7$ & 0.276 \\
\hline \multicolumn{5}{|l|}{ Appetite (\%) } \\
\hline Normal & $57 \cdot 4$ & $57 \cdot 4$ & $57 \cdot 1$ & $0 \cdot 214$ \\
\hline Better than normal & $11 \cdot 7$ & $12 \cdot 8$ & $9 \cdot 1$ & \\
\hline Worse than normal & $30 \cdot 9$ & $29 \cdot 8$ & $33 \cdot 8$ & \\
\hline \multicolumn{5}{|l|}{ Length of stay $(\%)$} \\
\hline$<7 d$ & $58 \cdot 5$ & $56 \cdot 9$ & $61 \cdot 8$ & 0.329 \\
\hline $7-14 d$ & 26 & $25 \cdot 8$ & $26 \cdot 4$ & \\
\hline $14-21 d$ & $9 \cdot 1$ & $10 \cdot 3$ & $6 \cdot 8$ & \\
\hline $1-2$ months & $3 \cdot 0$ & $3 \cdot 4$ & $2 \cdot 1$ & \\
\hline$>2$ months & $3 \cdot 4$ & $3 \cdot 6$ & $2 \cdot 9$ & \\
\hline \multicolumn{5}{|l|}{ Diet category (\%) } \\
\hline Standard/diabetic/cardiac menu & $66 \cdot 4$ & $66 \cdot 1$ & $66 \cdot 9$ & 0.582 \\
\hline High-protein/high-energy menu & $4 \cdot 6$ & $5 \cdot 4$ & $2 \cdot 9$ & \\
\hline Restricted diet for medical reasons & $6 \cdot 6$ & $6 \cdot 5$ & $6 \cdot 6$ & \\
\hline Minced or pureed diet & 0.6 & 0.7 & 0.4 & \\
\hline Not known & $21 \cdot 8$ & $21 \cdot 2$ & $23 \cdot 1$ & \\
\hline
\end{tabular}

ACHFPSQ, Acute Care Hospital Foodservice Patient Satisfaction Questionnaire.

Table 2 Percentage distributions of the ACHFPSQ items answered ( $n$ 603) and factor scores of the factors obtained by factor analysis: hospital patients aged 18+ years, Florence, Italy, November-December 2009

\begin{tabular}{|c|c|c|c|c|c|c|c|c|c|}
\hline \multirow[b]{2}{*}{ Statement (item) } & \multicolumn{5}{|c|}{ Percentage } & \multicolumn{4}{|c|}{ Factor } \\
\hline & Always & Often & Sometimes & Rarely & Never & $\mathrm{FQ}^{*}$ & $\mathrm{MSQ}^{*}$ & $\mathrm{HQ}^{*}$ & $\mathrm{SI}^{*}$ \\
\hline The meals have excellent and distinct flavours & $14 \cdot 3$ & $25 \cdot 7$ & $24 \cdot 1$ & $20 \cdot 7$ & $15 \cdot 2$ & 0.79 & & & \\
\hline The meals taste nice & $15 \cdot 1$ & $26 \cdot 4$ & $30 \cdot 7$ & $15 \cdot 4$ & $12 \cdot 4$ & $0 \cdot 76$ & 0.43 & & \\
\hline I like the way vegetables are cooked & $17 \cdot 1$ & $18 \cdot 6$ & $23 \cdot 4$ & $21 \cdot 6$ & $19 \cdot 3$ & 0.73 & $0 \cdot 37$ & & \\
\hline The hospital food has been as good as I expected & $18 \cdot 2$ & $25 \cdot 2$ & $25 \cdot 0$ & $19 \cdot 6$ & $12 \cdot 0$ & $0 \cdot 71$ & 0.42 & & \\
\hline Meat is tough and dry & $16 \cdot 3$ & $20 \cdot 1$ & $27 \cdot 5$ & $19 \cdot 7$ & $16 \cdot 4$ & $-0 \cdot 70$ & & & \\
\hline $\begin{array}{l}\text { The menu has enough variety for me to choose meals } \\
\text { I want to eat }\end{array}$ & $23 \cdot 3$ & $24 \cdot 1$ & $23 \cdot 1$ & $18 \cdot 1$ & $11 \cdot 4$ & 0.59 & $0 \cdot 32$ & $0 \cdot 37$ & \\
\hline Hot drinks are just the right temperature & $41 \cdot 1$ & $29 \cdot 9$ & $13 \cdot 9$ & $9 \cdot 6$ & $5 \cdot 5$ & & 0.77 & & \\
\hline Cold food is just the right temperature & $43 \cdot 6$ & $33 \cdot 5$ & $14 \cdot 4$ & $5 \cdot 2$ & $3 \cdot 3$ & & 0.75 & & \\
\hline Hot food is just the right temperature & $30 \cdot 9$ & $30 \cdot 9$ & $18 \cdot 1$ & $12 \cdot 1$ & $8 \cdot 0$ & $0 \cdot 35$ & 0.72 & & \\
\hline I am satisfied with meal distribution timest & $48 \cdot 8$ & $27 \cdot 0$ & $12 \cdot 2$ & $5 \cdot 5$ & $6 \cdot 5$ & & 0.42 & & \\
\hline I am satisfied with crockery and cutlery $\ddagger$ & $45 \cdot 3$ & $21 \cdot 8$ & $9 \cdot 4$ & $6 \cdot 2$ & $17 \cdot 3$ & & 0.45 & & \\
\hline I am still hungry after finishing the meal & $52 \cdot 7$ & $22 \cdot 7$ & $15 \cdot 6$ & $6 \cdot 0$ & $3 \cdot 0$ & & & 0.88 & \\
\hline I am hungry between consecutive meals & $36 \cdot 3$ & $24 \cdot 4$ & $24 \cdot 9$ & $10 \cdot 3$ & $4 \cdot 1$ & & & 0.83 & \\
\hline I received enough food & $56 \cdot 6$ & $26 \cdot 5$ & $9 \cdot 3$ & $4 \cdot 8$ & $2 \cdot 8$ & & 0.45 & 0.60 & \\
\hline Staff who take away my tray are friendly and polite & $70 \cdot 7$ & $20 \cdot 1$ & $5 \cdot 5$ & $2 \cdot 0$ & $1 \cdot 7$ & & & & 0.81 \\
\hline Staff who deliver my meals are neat and clean & $83 \cdot 4$ & $13 \cdot 4$ & $2 \cdot 3$ & 0.5 & $0 \cdot 4$ & & & & 0.77 \\
\hline Staff who deliver my meals are helpful & $60 \cdot 0$ & $23 \cdot 6$ & $8 \cdot 3$ & $4 \cdot 3$ & $3 \cdot 8$ & & & & 0.68 \\
\hline I am able to choose a healthy meal in hospital & $28 \cdot 2$ & $26 \cdot 6$ & $21 \cdot 8$ & $11 \cdot 1$ & $12 \cdot 3$ & $0 \cdot 48$ & 0.42 & & \\
\hline I like to be able to choose different sized meals & $32 \cdot 4$ & $25 \cdot 0$ & $20 \cdot 3$ & $11 \cdot 9$ & $10 \cdot 4$ & $0 \cdot 37$ & $0 \cdot 33$ & 0.42 & \\
\hline The hospital smells stop me from enjoying my meals & $9 \cdot 1$ & $10 \cdot 1$ & $20 \cdot 6$ & $17 \cdot 6$ & $42 \cdot 6$ & - & - & - & - \\
\hline \multirow{2}{*}{$\begin{array}{l}\text { I am disturbed by the noise of finished meal trays } \\
\text { being removed }\end{array}$} & $12 \cdot 3$ & $4 \cdot 6$ & $3 \cdot 9$ & $13 \cdot 0$ & $66 \cdot 2$ & - & - & - & - \\
\hline & Very good & Good & Okay & Poor & Very poor & & & & \\
\hline $\begin{array}{l}\text { Overall, how do you rate your satisfaction with } \\
\text { the food service? }\end{array}$ & $10 \cdot 0$ & $25 \cdot 8$ & $31 \cdot 9$ & $22 \cdot 7$ & $9 \cdot 6$ & & & & \\
\hline Eigenvalue & & & & & & $3 \cdot 48$ & $2 \cdot 74$ & $2 \cdot 17$ & 1.91 \\
\hline Explained variance (\%) & & & & & & $21 \cdot 7$ & $17 \cdot 2$ & $13 \cdot 5$ & $11 \cdot 9$ \\
\hline
\end{tabular}

ACHFPSQ, Acute Care Hospital Foodservice Patient Satisfaction Questionnaire; FQ, food quality; MSQ, meal service quality; HQ, hunger and quantity; SI, staff/service issues.

*Items with value $<0.40$ were not shown except for specific items. In bold, values of items used in factors.

tOriginal version: 'The cold drinks are just the right temperature'.

‡Original version: 'The crockery and cutlery are chipped and/or stained'.

Overall satisfaction was rated very good/good by one-third of the sample; one-third rated it sufficient and one-third as poor/very poor.
We found an association between the item 'I am still hungry after meals' and type of $\operatorname{diet}(P=0 \cdot 003)$. In particular, a majority of patients on special texture (minced/pureed) 
Table 3 Crude and adjusted analysis of patient characteristics, hospital admission and food catering factors in relation to overall perceived satisfaction (outcome): hospital patients aged 18+ years, Florence, Italy, November-December 2009

\begin{tabular}{|c|c|c|c|c|c|c|}
\hline \multirow[b]{2}{*}{ Exposure variable } & \multicolumn{3}{|c|}{ Crude $^{*}$} & \multicolumn{3}{|c|}{ Adjusted for other variablest } \\
\hline & OR & $95 \% \mathrm{Cl}$ & $P$ & OR & $95 \% \mathrm{Cl}$ & $P$ \\
\hline FQ factor & $6 \cdot 07$ & $4 \cdot 93,7 \cdot 48$ & $<0.001$ & $17 \cdot 21$ & $12 \cdot 27,24 \cdot 16$ & $<0.001$ \\
\hline MSQ factor & $2 \cdot 41$ & $2 \cdot 03,2 \cdot 85$ & $<0.001$ & $6 \cdot 16$ & $4 \cdot 71,8.06$ & $<0.001$ \\
\hline $\mathrm{HQ}$ factor & $1 \cdot 61$ & $1 \cdot 37,1 \cdot 89$ & $<0.001$ & 3.09 & $2 \cdot 45,3 \cdot 90$ & $<0.001$ \\
\hline SI factor & $1 \cdot 30$ & $1 \cdot 13,1 \cdot 51$ & $<0.001$ & $1 \cdot 75$ & $1 \cdot 44,2 \cdot 13$ & $<0.001$ \\
\hline I am disturbed by the noise of finished meal trays being removed & 0.99 & $0.91,1.07$ & 0.758 & $1 \cdot 00$ & & - \\
\hline The hospital smells stop me from enjoying my meals & $0 \cdot 88$ & $0.80,0.96$ & 0.003 & $1 \cdot 06$ & $0 \cdot 92,1 \cdot 23$ & 0.382 \\
\hline Age & $1 \cdot 01$ & $1 \cdot 01,1.02$ & $<0.001$ & 0.99 & $0.98,1.00$ & 0.207 \\
\hline \multicolumn{7}{|l|}{ Gender } \\
\hline Female & $1 \cdot 00$ & & - & $1 \cdot 00$ & & - \\
\hline Male & $1 \cdot 35$ & $1 \cdot 05,1 \cdot 72$ & $0 \cdot 018$ & 1.53 & $1 \cdot 06,2 \cdot 21$ & 0.024 \\
\hline \multicolumn{7}{|l|}{ Appetite } \\
\hline Normal & $1 \cdot 00$ & & - & $1 \cdot 00$ & & - \\
\hline Worse than normal & 0.36 & $0.27,0.48$ & $<0.001$ & $0 \cdot 78$ & $0.50,1 \cdot 24$ & 0.300 \\
\hline Better than normal & 1.06 & $0 \cdot 68,1 \cdot 70$ & 0.763 & $1 \cdot 24$ & $0 \cdot 70,2 \cdot 23$ & 0.457 \\
\hline \multicolumn{7}{|l|}{ Length of stay } \\
\hline$<7 \mathrm{~d}$ & $1 \cdot 00$ & & - & $1 \cdot 00$ & & - \\
\hline $7-14 d$ & 0.73 & $0.55,0.99$ & 0.040 & 0.92 & $0.59,1.45$ & 0.739 \\
\hline $14-21 d$ & $0 \cdot 33$ & $0.21,0.51$ & 0.001 & $0 \cdot 75$ & $0.38,1 \cdot 49$ & 0.415 \\
\hline 1-2 months & 0.46 & $0.21,0.99$ & 0.047 & 0.93 & $0 \cdot 33,2 \cdot 65$ & 0.899 \\
\hline$>2$ months & $0 \cdot 43$ & $0.21,0.85$ & 0.016 & 1.06 & $0.38,2 \cdot 93$ & 0.910 \\
\hline \multicolumn{7}{|l|}{ Type of diet } \\
\hline Standard/diabetic/cardiac menu & $1 \cdot 00$ & & - & & & \\
\hline High-protein/high-energy menu & $1 \cdot 72$ & $0.90,3.29$ & $0 \cdot 103$ & & & \\
\hline Restricted diet for medical reasons & 0.96 & $0 \cdot 70,1 \cdot 31$ & $0 \cdot 780$ & & & \\
\hline Minced or pureed diet & $1 \cdot 75$ & $0 \cdot 40,7 \cdot 64$ & 0.457 & & & \\
\hline Not known & $1 \cdot 32$ & $0 \cdot 78,2 \cdot 22$ & $0 \cdot 304$ & & & \\
\hline
\end{tabular}

$\mathrm{FQ}$, food quality; MSQ, meal service quality; $\mathrm{HQ}$, hunger and quantity; SI, staff/service issues.

*Odds ratios calculated with single variables (exposure) and overall perceived satisfaction (outcome).

tOdds ratios calculated with single variables (exposure), adjusted for all the others, and overall perceived satisfaction (outcome).

and high-protein diets answered that they were always hungry after meals.

Four dimensions of foodservice satisfaction were found by factor analysis: 'food quality' (FQ), 'meal service quality' (MSQ), 'hunger and food quantity' (HQ) and 'staff/service issues' (SI). The items used for factor analysis were seventeen out of twenty-one and explained $64 \cdot 3 \%$ of the total variance. In fact, four statements were excluded: (i) two statements were omitted because they were correlated with different factors making their interpretation ambiguous, i.e. 'I am able to choose a healthy meal in the hospital' (which had a correlation of 0.48 with FQ and 0.42 with MSQ) and 'I like to be able to choose different sized meals' (which had a correlation of 0.37 with FQ, 0.33 with MSQ and 0.42 with HQ; Table 2); and (ii) two statements were treated independently because they could have been included in a fifth factor, 'physical environment' (PE), which was not considered due to the insufficient number of items correlated with it, i.e. 'I am disturbed by the noise of finished meal trays being removed' (which had a correlation of 0.84 with PE) and 'The hospital smells stop me from enjoying my meals' (which had a correlation of 0.85 with $\mathrm{PE}$ ). The results of the univariate and multiple ordinal regression analyses are shown in Table 3 .

At univariate analysis all of the factors seemed to influence overall satisfaction (OS) significantly $(P<0 \cdot 001)$. In addition, the hospital smell item significantly and negatively influenced $\mathrm{OS}(\mathrm{OR}=0 \cdot 88, P=0 \cdot 003)$. Males emerged as being more satisfied with hospital foodservice than females $(\mathrm{OR}=1 \cdot 35, P=0 \cdot 018)$. A lower food intake than normal influenced $\mathrm{OS}$ negatively $(\mathrm{OR}=0 \cdot 36, P<0 \cdot 001)$. Length of stay seemed to have an inversely negative effect on OS. The type of diet did not influence OS. The adjusted model showed that all four factors remained significantly $(P<0 \cdot 001)$ associated with OS. In particular, for a one-unit change in $\mathrm{FQ}$, the odds of a higher level of OS increased 17.2-fold. Apart from the four factors, the only variable significantly associated with OS was gender, wherein the relationship with OS from the univariate analysis become stronger $(\mathrm{OR}=1.53 ; \quad P=0.024)$. Females seemed more critical than males: men had a $53 \%$ higher probability than women of positive judgement of overall quality.

\section{Discussion}

Some important aspects emerged from the present study: (i) regarding methodology, the questionnaire developed for English-speaking countries, which we adapted to Italy, proved to be practical; (ii) in line with other studies regarding perceived quality ${ }^{(31-33)}$, the most positively scored aspects of foodservice regarded staff and service, whereas food quality was considered less positive; (iii) the aspects that most influenced general satisfaction of patients 
were those related to food quality while aspects regarding staff, service, environment, patient characteristics and hospital admission emerged as less important; and (iv) we found some differences with respect to the structure of the published ACHFPSQ in some items which constitute it, in the loss of the PE factor and in the addition of the HQ factor. In particular, in our context, we found four factors underlying the twenty-one items: on the one hand, the extra three questions related to hunger and food quantity ('I am still hungry after finishing the meal', 'I am hungry between consecutive meals' and 'I received enough food') highlighted a new factor (HQ) which was not in the published ACHFPSQ; while on the other hand we did not have the PE factor. In fact, of the three items originally included in the Physical Environment dimension, one ('The hospital smells stop me from enjoying my meals') became part of the MSQ factor; the other two ('I am disturbed by the noise of finished meal trays being removed' and 'The crockery and cutlery are chipped and/or stained', the latter changed slightly in our adapted version to 'I am satisfied with crockery and cutlery') were included as independent variables in the multiple ordinal regression model because the factor would have been constituted only by two items and we decided to have factors only when the items were at least three ${ }^{(28)}$. In addition, the item 'I am satisfied with meal distribution time', which we introduced in the questionnaire, became part of the MSQ factor. Our questionnaire response rate was higher than those of other international studies $^{(17,24,34)}$.

Regarding use of the ACHFPSQ in the Italian context, we think that the questionnaire was well received by patients; this is also confirmed by the moderate/good response rate $(72 \%)$ compared with other studies ${ }^{(15,17,24,34)}$.

Contradictory results seemed to emerge in three items: $56.6 \%$ of the sample answered that they always received enough food, but $52.7 \%$ answered that they were always hungry after meals and $36 \cdot 3 \%$ that they were always hungry between meals (Table 2 ). However, these results may not be contradictory if patients received enough food but were unable to consume it for some reason, or were on a special diet and/or did not like the food and therefore did not eat it. The literature indicates that consumers with a good appetite may still have poor oral food intake owing to the food being placed out of reach, inability to handle cutlery, poor dentition, physical eating difficulties, meals being ordered too far in advance and a shortage of staff to encourage client intake and provide feeding assistance ${ }^{(17)}$.

All four factors obtained good Cronbach's alpha values (FQ, $\alpha_{\mathrm{C}}=0.74 ; \mathrm{MSQ}, \alpha_{\mathrm{C}}=0.73 ; \mathrm{SI}, \alpha_{\mathrm{C}}=0.65 ; \mathrm{HQ}$, $\alpha_{\mathrm{C}}=0 \cdot 74$ ), showing their good capacity to describe the underlying construct of the items. The first three values are consistent with those reported in the literature ${ }^{(24)}$ while the HQ factor, which is not in the published ACHFPSQ, had items which were well aggregated and had a good Cronbach's alpha. Regarding perception of the various aspects of foodservice, in our survey we can certainly state that patients rated staff/service issues very highly, while the food quality dimension was only rated as sufficient. This was also the result of previous studies using the ACHFPSQ: a one-day survey in 2005 (223 patients) was conducted in an acute-care private hospital, where staff/service issues were the most positively and food quality the least positively rated ${ }^{(34)}$; and a survey in 2006 (117 patients) was repeated twice due to introduction of off-site food preparation, but did not modify patients' perception of quality ${ }^{(35)}$. In our survey, satisfaction with food quality was certainly lower than previous findings but we do not know if this could be due to greater sample size or actual dissatisfaction.

Regarding the determinants of overall perceived quality among all factors, recent studies have reported that food quality (taste, presentation, flavour, preparation, variety) is the best predictor of overall satisfaction. Our multiple ordinal regression model to determine patients' overall satisfaction also identified FQ as the major aspect $(\mathrm{OR}=17 \cdot 2)$. On the other hand, previous authors have suggested that 'interpersonal' or service aspects (clean, friendly, polite, helpful nursing staff) were the most important ${ }^{(36,37)}$. In our model SI was the least important $(\mathrm{OR}=1 \cdot 75)$. In line with results in the literature ${ }^{(31,34,38)}$ our model also showed that associations between patients' characteristics (age, gender, appetite status, length of hospital stay) and overall satisfaction, which were all significant $(P<0 \cdot 01)$ in crude associations (apart from type of diet category), lost their explanatory power when adjusted for other variables (except gender, $P=0 \cdot 024$ ).

The four factors identified explained $64 \cdot 3 \%$ of the total variance in overall satisfaction, which is almost consistent with results in the literature ${ }^{(9,24,39)}$. Allowing patients to write comments on the survey was critical, as qualitative data provided in this manner can be used to support and enhance understanding of quantitative results. The comments also revealed new areas that could not be investigated but reflected patients' needs and influenced their perception of food quality. Several comments stressed the need for a wider variety of food, suggesting the possibility of ordering in advance and flexible menus, especially for patients with allergies or food intolerances and pregnant women. We noticed that many patients would also like to have individually packaged dressings (e.g. salt, pepper, oil, vinegar) while others understood the importance of a balanced diet low in salt. Although staff/service ranked high, it could still be improved: patients complained about hygiene and especially the absence of gloves. This may indicate a need for public/patient education more than a need to improve staff hygiene. The public in general has many misconceptions about the indications for gloves $v$. hand washing.

Patients hospitalized in departments far from the central kitchen complained about the temperature of hot food. Other authors have already shown that how food is 
delivered influences patient satisfaction: hospitals using a bulk trolley method of food distribution provided food with better texture, temperature and flavour ${ }^{(31,40-42)}$.

Since to our knowledge the present study is one of the first conducted in an Italian hospital using the ACHFPSQ, we have to consider two aspects in benchmarking our results with similar European studies: (i) none of the statements refer to culinary tradition, which is recognized as an Italian prerogative; and (ii) our sample was bigger than those of other studies ${ }^{(17,24,34,35)}$ and this may increase the significance of our findings. The first point may raise the satisfaction threshold slightly, because perceived food quality was lower than in other European countries.

However, the research has some limits, the first being that patients' overall satisfaction with foodservice is difficult to measure and quantify since it is largely subjective and influenced by many variables. The ACHFPSQ focuses on many aspects of foodservice overall satisfaction, but there are still aspects of quality that the questionnaire could miss. For example, we were aware that distribution times of meals could be relevant to determinate overall satisfaction and we added this question ${ }^{(18,25)}$. On the other hand, too long a questionnaire could annoy patients, making some answers less reliable. Moreover, other study results $^{(4,43,44)}$ indicate that variables such as pain, anxiety, irritable bowel syndrome, loss of sense of taste and depression may play an important role in the way patients reply to questions. It is also difficult to establish a cut-off of patient satisfaction, as there are few studies measuring hospital foodservice aspects with this validated instrument. Another aspect is that the sickest patients have low motivation to fill in questionnaires, as do patients with non-Italian speaking backgrounds. As we mentioned in the inclusion criteria, patients were not enrolled in the study if nursing staff considered their condition too poor or if they were not served food (no oral diet) or were too confused to answer or provide consent. Critical, very elderly and disabled patients were therefore presumably left out of the study, affecting the representativeness of the patient population. However, since the response rate was higher than in previous studies and there were no differences in the characteristics of respondents and non-respondents to all ACHFPSQ items, we believe that the effect of a selection bias is limited.

\section{Conclusions}

Lack of appetite for medical reasons is probably the main cause of malnutrition in hospitals. Our study also aimed to provide a basis for improving patients' nutrient intake to accelerate recovery and to reduce the length of hospital stay. In conclusion, our findings suggest that the following improvements are possible: a wider menu, information on ingredients and better timing, distribution and presentation of food. These aspects should of course be added to those found by the questionnaire, such as how vegetables are cooked and why all foods tend to taste the same. To improve food quality, it may be necessary to train operators to choose high-quality primary materials according to Ministry for Health hospital food guidelines, which encourage local sourcing of ingredients and organic production ${ }^{(45)}$.

The items regarding the role of hospital staff on overall quality were found to be the most positively rated but not the most determining. We highlight this aspect because it has a positive influence on patients' experience of hospital food ${ }^{(32)}$.

\section{Acknowledgements}

This research received no specific grant from any funding agency in the public, commercial or not-for-profit sectors. The authors declare that they have no conflicts of interest. G.M. collaborated in performing the study, carried out the data analysis and wrote the article; R.F. had the idea for the article, collaborated in the study design, collected the data and reviewed the drafts of the manuscript; F.V. performed the literature research, collaborated in the study design, collaborated in writing the article and reviewed the drafts of the manuscript; F.N. collaborated in the study design, made data available and coordinated the data collection, helped to conceptualize ideas and reviewed the drafts of the manuscripts; C.Q. collaborated in performing the data analysis, collaborated in writing the article, helped to conceptualize ideas and reviewed the drafts of the manuscripts; N.N. collaborated in performing the study, supervised the work, helped to conceptualize ideas and reviewed the drafts of the manuscripts. All the authors contributed to conception of the article, drafting and revision of content. All the authors have seen and approved the contents of the submitted manuscript. The authors thank Dr Olivia Wright for providing the questionnaire for their study.

\section{References}

1. Lassen KO, Kruse F \& Bjerrum M (2005) Nutritional care of Danish medical in patients - patients' perspectives. Scand J Caring Sci 19, 259-267.

2. Rasmussen HH, Holst M \& Kondrup J (2010) Measuring nutritional risk in hospitals. Clin Epidemiol 2, 209-216.

3. Sauerwein HP \& Serlie MJ (2010) Optimal nutrition and its potential effect on survival in critically ill patients. Neth J Med 68, 119-122.

4. St-Arnaud-McKenzie D, Paquet C, Kergoat MJ et al. (2004) Hunger and aversion: drives that influence food intake of hospitalized geriatric patients. J Gerontol A Biol Sci Med Sci 59, 1304-1309.

5. Ruxton CH, Gordon J, Kirkwood L et al. (2008) Risk of malnutrition in a sample of acute and long-stay NHS Fife in-patients: an audit. J Hum Nutr Diet 21, 81-90.

6. Hickson M, Fearnley L, Thomas J et al. (2007) Does a new steam meal catering system meet patient requirements in hospital? J Hum Nutr Diet 20, 476-485. 
7. Naithani S, Whelan K, Thomas J et al. (2008) Hospital inpatients' experiences of access to food: a qualitative interview and observational study. Health Expect 11, 294-303.

8. O'Flynn J, Peake H, Hickson M et al. (2005) The prevalence of malnutrition in hospitals can be reduced: results from three consecutive cross-sectional studies. Clin Nutr 24, 1078-1088.

9. Dube L, Trudeau E \& Belanger MC (1994) Determining the complexity of patient satisfaction with foodservices. $J \mathrm{Am}$ Diet Assoc 94, 394-398, 401.

10. Gedrich K (2003) Determinants of nutritional behaviour: a multitude of levers for successful intervention? Appetite $\mathbf{4 1}$, 231-238.

11. O'Regan P (2009) Nutrition for patients in hospital. Nurs Stand 23, 35-41.

12. Watters CA, Sorensen J, Fiala A et al. (2003) Exploring patient satisfaction with foodservice through focus groups and meal rounds. J Am Diet Assoc 103, 1347-1349.

13. Quercioli C, Marianelli RB, Conti S et al. (2011) Nutritional counselling and its effects on diet, nutritional knowledge and status, physical activity and quality of life in a Southern Europe population: evaluation of a health promotion programme. Ital J Public Health $\mathbf{8}, 8$.

14. King SC, Meiselman HL, Hottenstein AW et al. (2005) The effects of contextual variables on food acceptability: a confirmatory study. Food Qual Prefer 18, 58-65.

15. Wright O, Capra S \& Aliakbari J (2003) A comparison of two measures of hospital foodservice satisfaction. Aust Health Rev 26, 70-75.

16. Donini LM, Castellaneta E, De Guglielmi S et al. (2008) Improvement in the quality of the catering service of a rehabilitation hospital. Clin Nutr 27, 105-114.

17. Wright OR, Connelly LB \& Capra S (2006) Consumer evaluation of hospital foodservice quality: an empirical investigation. Int J Health Care Qual Assur Inc Leadersh Health Serv 19, 181-194.

18. Donini LM, Castellaneta E, Magnano L et al. (2003) The quality of a restaurant service at a geriatric rehabilitation facility. Ann $\operatorname{Ig}$ 15, 583-600.

19. Regione Toscana (2009) Toscana in cifre Sistema Statistico Regionale, Sanità e Salute. http://ius.regione.toscana.it/cif/ stat/index-sanita.shtml (accessed April 2011).

20. Todorovic V, Russell C, Stratton R et al. (2003) The 'MUST' Explanatory Booklet A Guide to the 'Malnutrition Universal Screening Tool' ('MUST') for Adults. Redditch: BAPEN.

21. Theurer VA (2011) Improving Patient Satisfaction in a Hospital Foodservice System Using Low-Cost Interventions: Determining Whether a Room Service System is the Next Step. All Graduate Reports and Creative Projects, Paper no. 32. Logan, UT: Utah State University; available at http://digitalcommons.usu.edu/gradreports/32

22. Lau C \& Gregoire MB (1998) Quality ratings of a hospital foodservice department by inpatients and postdischarge patients. J Am Diet Assoc 98, 1303-1307.

23. Ferguson M, Capra S, Bauer J et al. (2001) Development of a patient satisfaction survey with inpatient clinical nutrition service. Aust J Nutr Diet 58, 157-163.

24. Capra S, Wright O, Sardie M et al. (2005) The Acute Hospital Foodservice Patient Satisfaction Questionnaire: the development of a valid and reliable tool to measure patient satisfaction with acute care hospital foodservice. Foodservice Res Int 16, 1-14.

25. Donini LM, Riti M, Castellaneta E et al. (2009) A survey on diet manuals in Italian hospitals. Ann $\operatorname{Ig} 21,575-585$.
26. Firenze A, Morici M, Calamus G et al. (2009) Evaluation of customer satisfaction with the hospital catering system in the city of Palermo (Italy). Ig Sanita Pubbl 65, 29-39.

27. Ferber R (1977) Research by convenience. J Consum Res $\mathbf{4}$, $57-58$.

28. Norman GR \& Streiner DL (2008) Biostatistics: The Bare Essentials. Hamilton, ON: BC Decker Inc.

29. King G, Honaker J, Joseph A et al. (2001) Analyzing incomplete political science data: an alternative algorithm for multiple imputation. Am Polit Sci Rev 95, 49-69.

30. O'Reilly GM, Jolley DJ, Cameron PA et al. (2010) Missing in action: a case study of the application of methods for dealing with missing data to trauma system benchmarking. Acad Emerg Med 17, 1122-1129.

31. Hartwell HJ, Edwards JS \& Beavis J (2007) Plate versus bulk trolley food service in a hospital: comparison of patients' satisfaction. Nutrition 23, 211-218.

32. Johns N, Hartwell H \& Morgan M (2010) Improving the provision of meals in hospital. The patients' viewpoint. Appetite 54, 181-185.

33. Tranter MA, Gregoire MB, Fullam FA et al. (2009) Can patient-written comments help explain patient satisfaction with food quality? J Am Diet Assoc 109, 2068-2072.

34. Fallon A, Gurr S, Hannan-Jones MD et al. (2008) Use of the Acute Care Hospital Foodservice Patient Satisfaction Questionnaire to monitor trends in patient satisfaction with foodservice at an acute care private hospital. Nutr Diet $\mathbf{6 5}$, $41-46$.

35. Porter J \& Cant R (2009) Exploring hospital patients' satisfaction with cook-chill foodservice systems: a preliminary study using a validated questionnaire. $J$ Foodservice 20, 81-89.

36. Gregoire MB (1994) Quality of patient meal service in hospitals: delivery of meals by dietary employees vs delivery by nursing employees. J Am Diet Assoc 94, 1129-1134.

37. Tomes AE \& Chee Peng Ng S (1995) Service quality in hospital care: the development of an in-patient questionnaire. Int J Health Care Qual Assur 8, 25-33.

38. DeLuco D \& Cremer M (1990) Consumers' perceptions of hospital food and dietary services. J Am Diet Assoc 90, $1711-1715$.

39. Belanger MC \& Dube L (1996) The emotional experience of hospitalization: its moderators and its role in patient satisfaction with foodservices. J Am Diet Assoc 96, 354-360.

40. Edwards JS \& Hartwell HJ (2006) Hospital food service: a comparative analysis of systems and introducing the 'Steamplicity' concept. J Hum Nutr Diet 19, 421-430.

41. O'Hara P A, Harper DW, Kangas M et al. (1997) Taste, temperature, and presentation predict satisfaction with foodservices in a Canadian continuing-care hospital. $J \mathrm{Am}$ Diet Assoc 97, 401-405.

42. Reglier-Poupet H, Parain C, Beauvais R et al. (2005) Evaluation of the quality of hospital food from the kitchen to the patient. J Hosp Infect 59, 131-137.

43. Monsbakken KW, Vandvik PO \& Farup PG (2006) Perceived food intolerance in subjects with irritable bowel syndrome - etiology, prevalence and consequences. Eur J Clin Nutr 60, 667-672.

44. Simmons SF, Cleeton P \& Porchak T (2009) Resident complaints about the nursing home food service: relationship to cognitive status. J Gerontol B Psychol Sci Soc Sci 64, 324-327.

45. Ministero della Salute (2011) Linee di indirizzo nazionale per la ristorazione ospedaliera e assistenziale. Gazzetta Ufficiale Italiana no. 37 supplement 39 attach A. 